\author{
by L.J.F. (Jo) Hermans \\ Leiden University, The Netherlands - Hermans@Physics.LeidenUniv.nl - DOI: 10.1051/epn/2014202
}

\title{
Mobility and payload
}

We hen moving around, our energy efficiency is heavily influenced by the ratio of the mass being transported to the mass of the vehicle which does the transporting. Professionals call it the 'Payload Fraction'. Let us call it the PF for simplicity. When we mount our bicycle, we are extremely lucky: the PF is much larger than 1. For a typical cyclist (assumed to be not particularly heavy) we find the PF to be around 5. Cars are nowhere near such high value. If driven by a single person, we find a PF around 0.05, and for a full car around 0.25. Can this compete with trains? That depends: typically trains have a PF of 0.10 to 0.20 while light-weight trains can reach a PF of more than 0.35 if people are willing to stand.

But the really interesting case is the airplane. The reason is the energy source. Whereas electric trains do not have to carry their fuel, planes do. And this makes quite a difference. Remember the traditional rule of thumb: irrespective of the type, planes used to consume $10 \mathrm{~cm}^{3}$ of fuel per seat per second, or 36 litres per hour. With recent improvements in efficiency, let us assume that 25 litres per seat and per hour is a fair number. For short flights of an hour or so, this does not represent a tremendous extra weight per passenger, and hardly influences the payload. However, for long-distance flights this is a different story. Take a flight from Paris to Cape Town, or from Amsterdam to San Francisco. These take more than 10 hours, so the fuel per passenger that the plane has to carry is around 250 litres at take-off. This is several times the mass of the passenger, so it has a pretty devastating impact on the payload. The first lesson we learn is that short flights have a much better PF than long ones. Planes like the Embraer 190 and the Fokker 100, designed for short distances, achieve PF values of 0.35 (for maximum payload and maximum take-off weight). Not bad if we compare it to a car.

Now what about long distances? Let us look at a real case: the big, double-decker Airbus 380 which is designed for long-haul distances. Its 'operational empty weight' is some 270 tons. The maximum amount of fuel it can load is 250 tons. This is in line with the above rule of thumb if we consider that the number of passengers is around 700 (it varies from 550 to 850 , depending on seating arrangement) and realise that some extra fuel should be taken on board for takeoff and landing. So, refuelling the empty aircraft practically doubles its weight! The result is that the PF for maximum take-off weight is 0.21 only. Other long-haul planes like the much smaller Boeing 787 Dreamliner have the same value.

Now one would be tempted to think that the heavy fuel load of long-range, four-engine planes like the Airbus 380 or the Boeing 747 explains why they climb so slowly after takeoff, if you compare it with two-engine planes. Wrong. The real reason is that safety rules require that an aircraft must be able to continue its take-off even if one engine goes dead. This means that, if everything works properly, four-engine planes have a $33 \%$ power surplus, whereas two-engine planes have a full $100 \%$ surplus.

So it's not always the physicist who determines the behaviour of an aircraft, nor the technician. Sometime it's our safety. 